\title{
Practical Research on Protection and Utilization of Urban Spatial Water Elements from the Perspective of Healthy Cities
}

\author{
Jiao Yang ${ }^{1}$, Chen Shi $^{1}$, and Yuan Jingcheng ${ }^{1, *}$ \\ ${ }^{1}$ Shenyang Jianzhu University, School of Architecture and Urban Planning, No.9 Hunnan East Road, Hunnan New District, Shenyang, \\ China
}

\begin{abstract}
The healthy development of urban elements would be important to sustainable urban development, especially the elements of water resources. This paper discusses the key points and methods of water elements development and protection in urban design for Healthy-city, taking the design of China Ceramic Valley in Liling as an example. Based on the analysis of hydrological and geographic data, it establishes the network structure of the river system, summarizes systematic measures for the guidance and control of sponge cities, puts forward the optimization and control methods of waterfront spatial form and compiles quantitative and elastic space guidelines. The results show that the whole-scale and systematic urban design is a necessary step of urban water resources protection and utilization. It provides practical experience and process reference for urban health and sustainable development.
\end{abstract}

\section{Introduction}

The topic of human-water relations has accompanied the whole process of the origin and development of human civilization. The will of human beings to coexist with water and to live by water has never changed, although the relationship between human beings and water changed from confrontation to coexistence, in the development process from primitive civilization to industrial civilization and then to ecological civilization. However, the continuous destruction and consumption of the water environment in the traditional urbanization process have gradually separated the healthy development relationship between humans and water, and the sustainable development of the city has received enormous challenges. Now, urban development has entered the stage of ecological civilization in China, which takes the protection and efficient utilization of space resources as the theme. How to scientifically and rationally protect and utilize water resources elements in urban spatial and form a healthy relationship between human beings and water has become a hot issue in urban design research again. The paper discusses the process and method of water resource protection and utilization in urban spatial from the perspective of urban design, taking the project practice of the China Ceramic Valley (CCV) as an example. It provides theoretical exploration and practical reference for the study of healthy cities and waterfront space design.

The CCV is located in the western of Liling city center, Hunan Province (Fig. 1 \& 2). Liling has a convenient transportation location, a long history and rich regional culture, where is the birthplace of underglaze color porcelain. It is one of five major ceramic industry bases in China and the key development area of "Changsha-
Zhuzhou-Xiangtan" city group. The CCV (design area $16.64 \mathrm{~km} 2$ ) has the topography characteristics of "ShanShui City" with the Mount Weishan, Mount Shigong and Mount Fenghuang distributed in a triangle, and the Lujiang River in the south connected with a plurality of corridors collecting water (Fig. 3). On the whole, the CCV has an excellent ecological background and a strong trend of urban expansion.

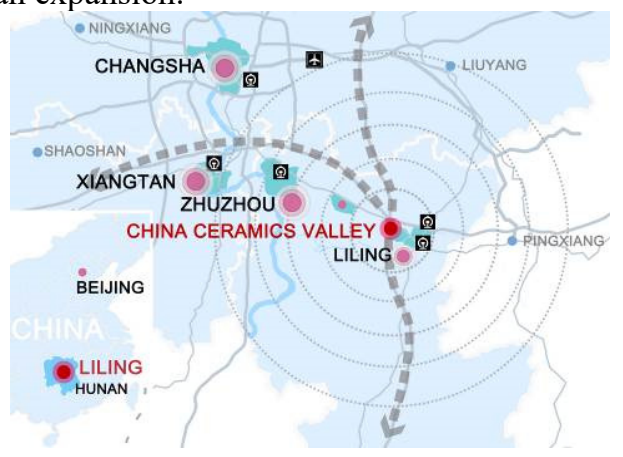

Fig. 1. Location of the CCV

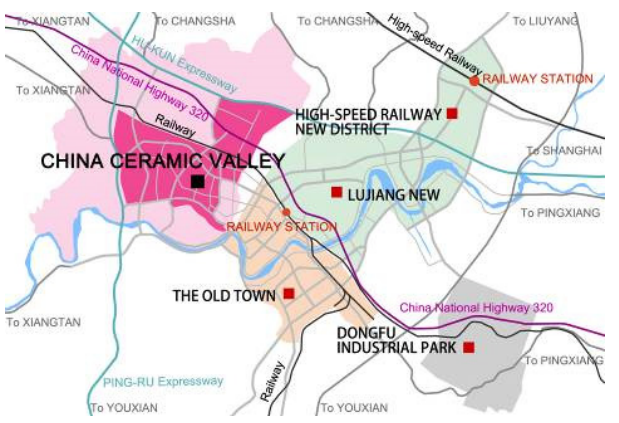

Fig. 2. Industrial Layout of Liling

" Corresponding author: xjdgh2009@163.com 


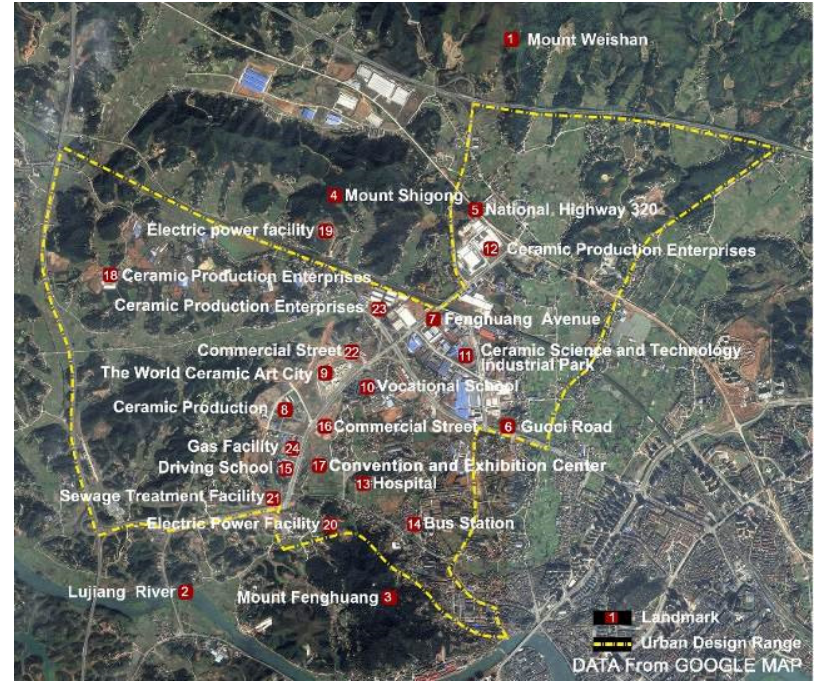

Fig. 3. Current Situation of the CCV

\section{Methods and Analysis}

A healthy city should be a way of life that city residents enjoy and adapt to the natural environment and harmonious community. The core task of urban design for a healthy city is to make rational use of space resources and environmental elements to create a suitable space environment. Its content and scope involve the overall planning, detailed planning, plots and architectural design, covering all stages of urban space planning. Therefore, the design of water environment elements also includes different design contents in different design scales.

At the urban scale, the key content is to deal with the coupling relationship between water space and urban form. It protects the hydrological cycle process and water ecological function system, for guiding the safe and efficient development of urban construction.

At the regional scale, the design structures the system of Sponge-city according to the characteristics of precipitation and run-off. It put forward specific control requirements and indicators from the perspectives of water ecology, water environment and water safety. Through the control contents of Sponge-city, which is implemented systematically and level-by-level, it put forward requirements and indicators for detailed planning and architectural design.

At the block scale, it includes the multi-plan comparative process for the waterfront space and water landscape from the hydrophilic body feeling and visual perception, to improve the accessibility and comfort of
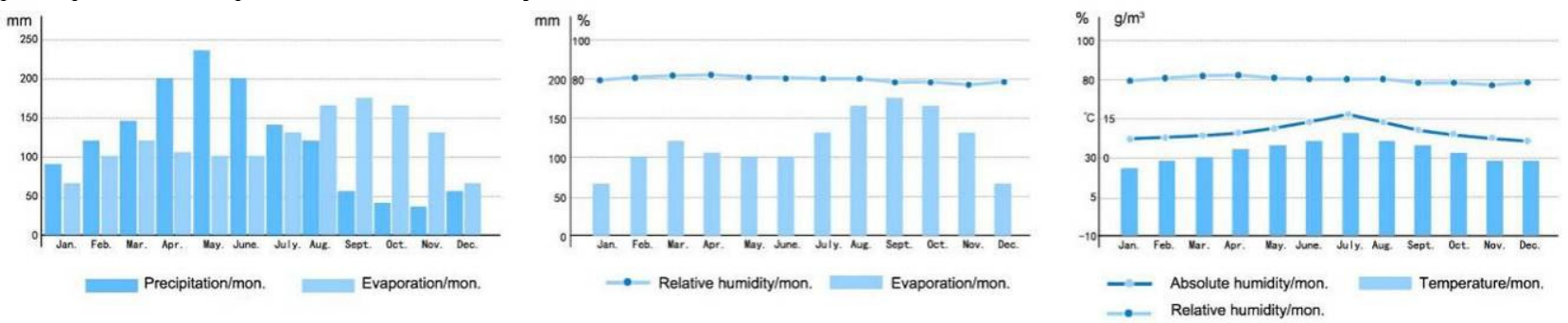

\subsubsection{Analysis of Climate-oriented Hydrological Characteristics}

The urban design comprehensively analyzed the regional climatic conditions and hydrological cycle process before space design (Fig. 4). Liling is subtropical monsoon climate located between the two sub-rainy centers in eastern and southern Hunan, with annual average rainfall of $1425.9 \mathrm{~mm}$, minimum annual rainfall of $1028.6 \mathrm{~mm}$, and air relative humidity maintained at $80 \%$ level for a long time. Based on the analysis of rainfall data in Liling in recent 30 years, the region has a medium rainfall status in Hunan province and is a region with abundant rainfall nationwide. According to the data analysis, the average annual precipitation reached $629.3 \mathrm{~mm}$, but the rainfall was extremely uneven in monthly. The rainy season was from April to June, and the rainfall was the highest in May (up to $233.2 \mathrm{~mm}$ ). From September to the next year, the monthly average is below $100 \mathrm{~mm}$, with the least in September and December (both less than $53 \mathrm{~mm}$ ). The annual average temperature is about $18^{\circ} \mathrm{C}$, the annual average frost-free period is 288 days. Furthermore, the geomorphology of CCV is dominated by low hills, with plains accounting for $16 \%$ and waters for $5 \%$. The soil composition is dominated by shale, accounting for $47.8 \%$. The instantaneous run-off during rainfall is large, and the surface run-off intensity will be increased after the hardening of the urban underlying surface. Therefore, climate characteristics put forward requirements for the design, which is to ensure smooth catchment run-off corridor and control surface run-off of construction land at the initial stage of rainfall.

Fig. 4. Data Analysis of Climate and Hydrological 


\subsubsection{Construction of Water System Network}

Based on the analysis of natural climate, hydrological conditions, topography, soil and vegetation, the urban design evaluates the suitability of land development and constructs a water system network including the following three steps.

(1) Through the analysis of terrain data by GIS, the natural catchment line and catchment area are extracted (Fig. 5), the study calculates total and hourly flow of the rainfall and run-off in each catchment area, and constructs the urban water system network based on the natural catchment network.

(2) By using hydrological simulation tools, it analyzes the threat of flood from Lujiang River and mountains to urban space (Fig. 6) and carries out spatial control for flood passage and flooded area to improve urban water safety control level.

(3) The design delimits the ecological red line of urban construction, based on the overlaying of the water system network, wind corridor, sight corridor and habitat corridor. The water network closed to nature can maximize the efficiency of ecosystem services, emphasizes the coupling and coordination of land use and water environmental benefits.

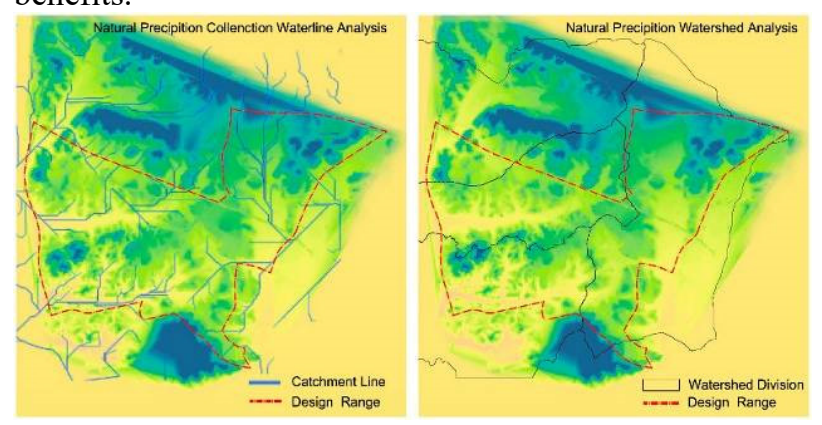

Fig. 5. Analysis of Precipitation Run-off
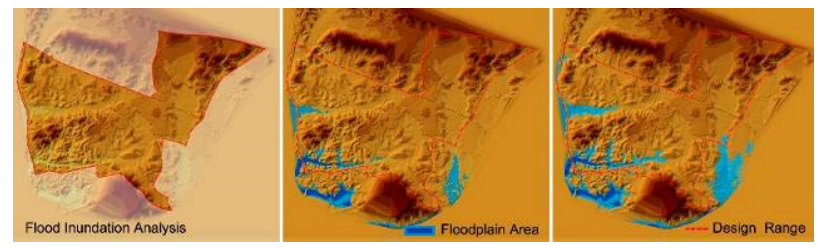

Fig. 6. Safety Analysis of Rainfall and Flood

\subsubsection{Management of the Small Watershed}

The design protects water ecology through watershed classified management, dividing the design scope into 26 small watersheds, which are controlled in two types (Fig. 7). The first type is the closed watershed: rainwater storage is required to reach the overall planning goal, and the water quality can be controlled under maximum pressure reduction. The second is the unclosed watershed: the hydrological characteristics of the basin will remain unchanged within the design scope, and the storage target of rain and flood will be controlled without increasing the burden outside the scope. Then, through the integration and adjustment of large watersheds, water resources can be allocated with similar watersheds to reach a balance in the whole watershed. Classified small watershed management and control measures effectively decompose water ecological objectives, improve the self-purification efficiency of ecosystems, reduce the degree of human impact in urban space, and strive to maximize the protection of natural ecosystems.

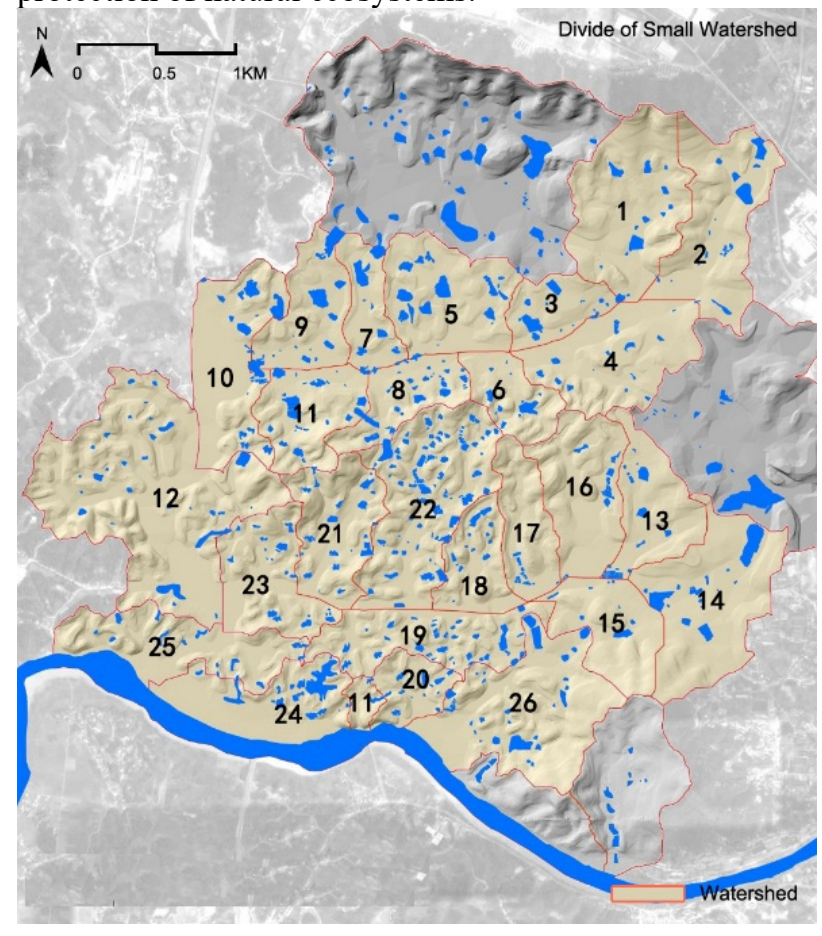

Fig. 7. Management of Small Watershed

\subsection{Construction of Sponge City System}

\subsubsection{Comparative Selection of Development Models}

The changes in precipitation and run-off brought by the development and construction of urban space affect the urban natural ecosystem. The urban design pays attention to the interaction and influence law between water resources and land-use, carries out a comparative study on the interaction between land development and rainfall runoff of the multiple spatial designs. Based on analyzing the current situation of soil and water relations in the area, the "Fast-drainage Mode" dominated by municipal infrastructure and the "Sponge-city Mode" dominated by low-impact development are compared (Fig. 8). The results show that the design with the Sponge-city Model takes a great conjugate relationship between the value of water resources and land development. It will realize a win-win development of urban space water resources and land development. On this basis, the design carried out indepth sponge-city system research, setting up a control system with annual run-off total amount control as the core control requirement.

\subsubsection{Division Control of Sponge-city System}

The urban design introduces the low-impact development technology under the framework of Sponge-city. It puts forward hierarchical control strategy, content and requirements in the overall design stage, and decompose 
and implement the control requirements in the detailed design stage. The design area is divided into the best construction area, the suitable construction area, the conditional construction area and the non-construction area by superposition analysis of various data layers. For the best and suitable area, the Sponge-city system construction low-impact development measures abbreviated as "infiltration", "storage", "retention" and "purification". The choice of measures in these areas is not limited by topography and environment, thus achieving maximum efficiency utilization. The conditional construction area exists problems such as poor retention capacity generally. Sponge-city measures focus on measures such as "storage", "infiltration" and "purification". There are many restrictive conditions in the non-construction area for construction, such as the terrain slope, elevation, ecological conservation and point source pollution. The "clean" treatment and ecological conservation function construction would be considered as far as possible for these areas. The multi-level division control process protects ecologically sensitive area such as natural landform, vegetation, water system and wetland effectively, and improve the run-off control and pollution purification capacity of the design area.

\subsubsection{Quantitative and Elastic Index Control}

The guiding control of Sponge-city applies the principle of zoning quantitative control, and the design area is divided into five control zones according to the natural basement conditions and the type of development land. It establishes a guidance and control index system including 22 indexes in four aspects (water ecology, water safety, water environment and water resources), and determines the threshold value of each quantitative control index according to different zoning types threshold value. Considering the elastic control of each region, the control indicators are divided into mandatory and guiding categories. The mandatory indicators include annual runoff total vacancy rate, water ecological shoreline renovation rate, flood control standard, NH3-N reduction rate and rainwater utilization rate. The guiding indicators include light sinking LID area, green roof area, permeable pavement area and COD pollution reduction amount. Furthermore, for different types of construction land, such as residential land, public management, commercial land and green space, the system puts forward targeted index requirements, including permeable road surface rate, sinking green space rate and biological detention facilities rate.

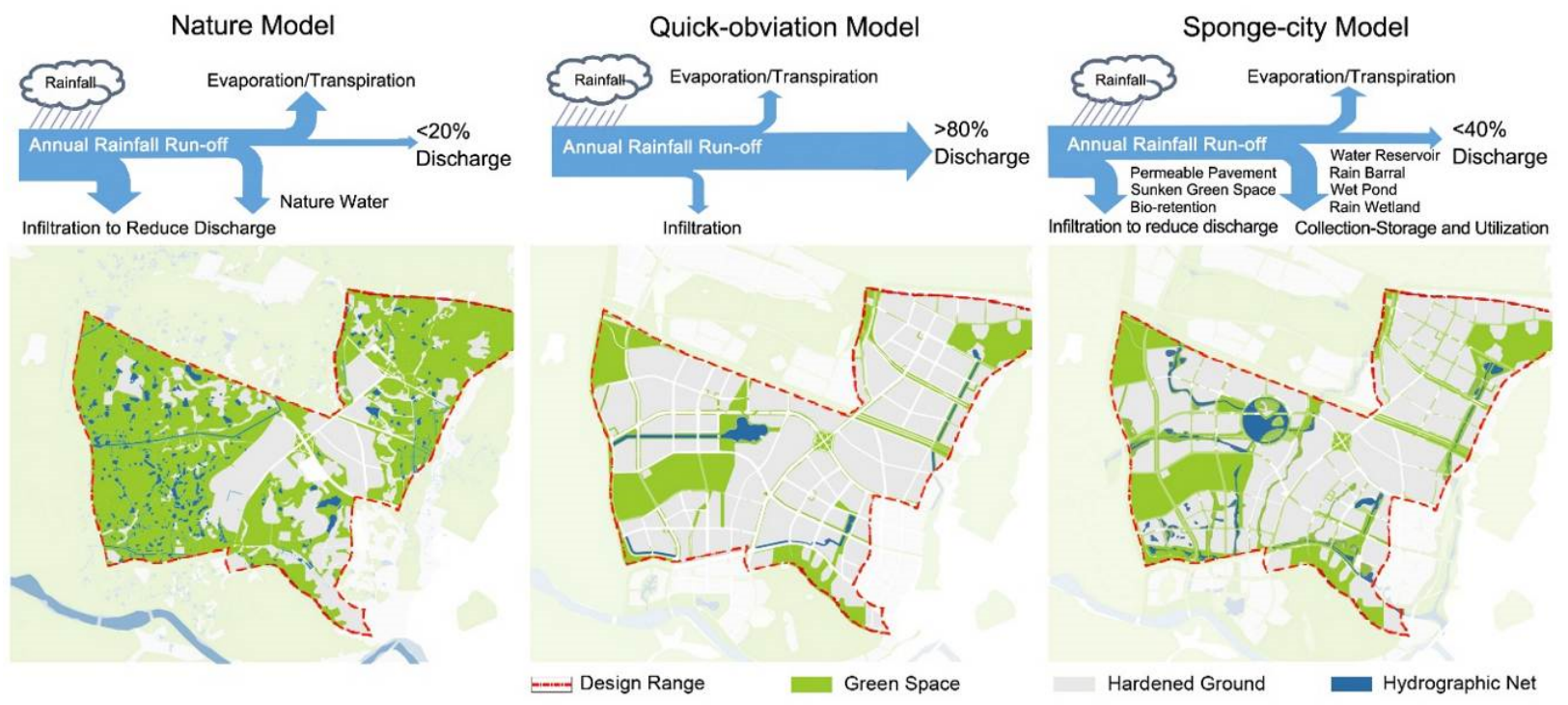

Fig. 8. Contrastive Choice of Development Modes

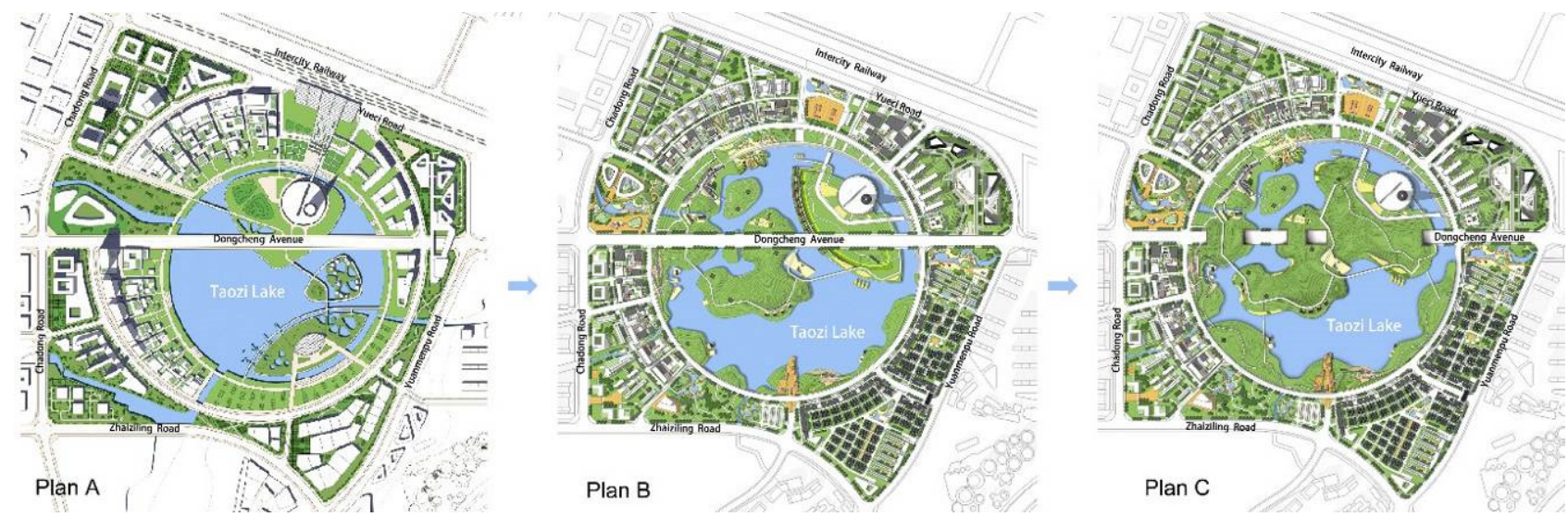

Fig. 9. Optimizing Process of Waterfront Space Design 


\subsection{Control of Waterfront Spatial Form}

\subsubsection{Multi-plan Comparison of Core Nodes}

Taozi Lake Area is the core of the CCV and the key node of the urban design. The design plans an open lake in the center of the Taozi Lake area to meet the needs of the water system ecological storage and urban core landscape, to activate the vitality of industrial chain and urban space, and to provide more approachable waterfront public space. Based on the hydrological analysis at the overall level, the water body of Taozi Lake is required to have the function of storing and buffering rainfall run-off. For the storage requirements of the Sponge-city, the water area of Taozi Lake should be about 20 hectares. Therefore, under the guidance above, the design deepens the waterfront space form design. The spatial form of the Taozi Lake undergoes several rounds of optimization, mainly including three optimization processes (Fig. 9). Firstly, based on the overall urban design, it designs a lake consisting of annular lake surface and regular geometric islands (Plan A). Secondly, for increasing the utilization ratio of hydrophilic coastline and reflecting the artistic conception of Chinese traditional garden, the detailed design optimizes the lake shoreline of the free form for the inner island (Plan B). In the aspect of shoreline utilization, it adds ecological coastline and tourist trail trestle to improve the hydrophilicity and accessibility of waterfront space. Thirdly, in order to improve the walking connectivity and landscape continuity of the area, reduce the impact of traffic separation of the national porcelain road, it uses the undulating terrain to separate the main road (Guoci Road) from the walking network in three dimensions (Plan $\mathrm{C}$ ), reducing the mutual interference between people and vehicles, improving the continuity of the landscape and realizing the artistic conception of waterfront space in different walking scenes.

\subsubsection{Design of Regulation and Storage System}

It is an important task to realize the self-regulation and storage of Taozi Lake ecologically. The lake body design adopts the method of multi-level water storage and overflow seepage to reduce the degree of water level affected by seasonal changes (Fig. 10).

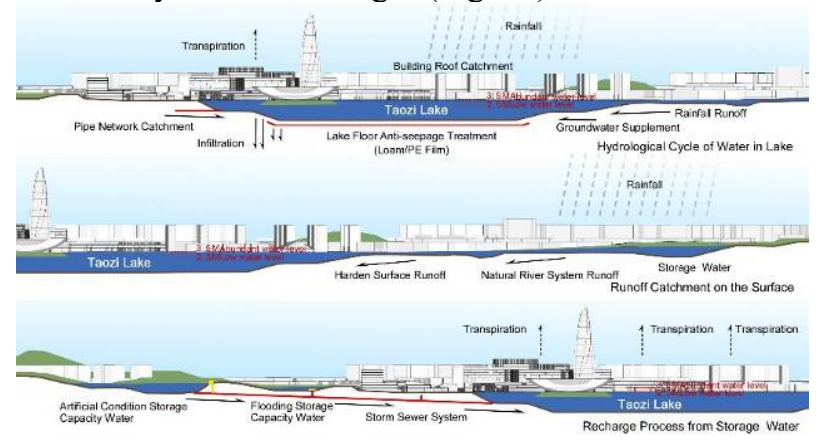

Fig. 10. The Water Storage System of Taozi Lake

It takes a comprehensive calculation of the annual monthly average rainfall, inflow, evaporation, infiltration and other data, simulates the water level changes and sets the high water level and low water level different multilevel waterfront landscape form. At the same time, it sets the overflow bank wetland and the water storage reflux system for extreme rainfall. Various water body regulation and storage designs ensure the relative stability of the lake water level, ensure the water landscape features presenting a relatively stable, under different meteorological conditions.

\section{Results and discussion}

\subsection{Urban Design of Water and Land-use Conjugation}

The urban design establishes a network and hierarchical water system network pattern, including "one lake, multiple waterways and multiple nodes". It takes the water system network as a frame to establish the green space network (Fig. 11), based on the analysis and superposition of meteorological, topographic, vegetation, soil and other environmental data. Firstly, the design ensures a smooth flow of the water system by protecting the strip-shaped green corridor along with the water system. Secondly, the run-off water quality is purified and the pollution of nonpoint source pollution to river water is reduced by controlling the shape of the green space in the small watershed plane retention buffer zone. Thirdly, it optimizes the spatial form of water and green space at important nodes to improve the ability to regulate and store run-off. The hydrological process closed to the natural is the foundation to ensure the health of the water environment. It provides a basic condition for the win-win of urban development and environmental protection. This win-win development is called the Conjugation of Water and Land-use.

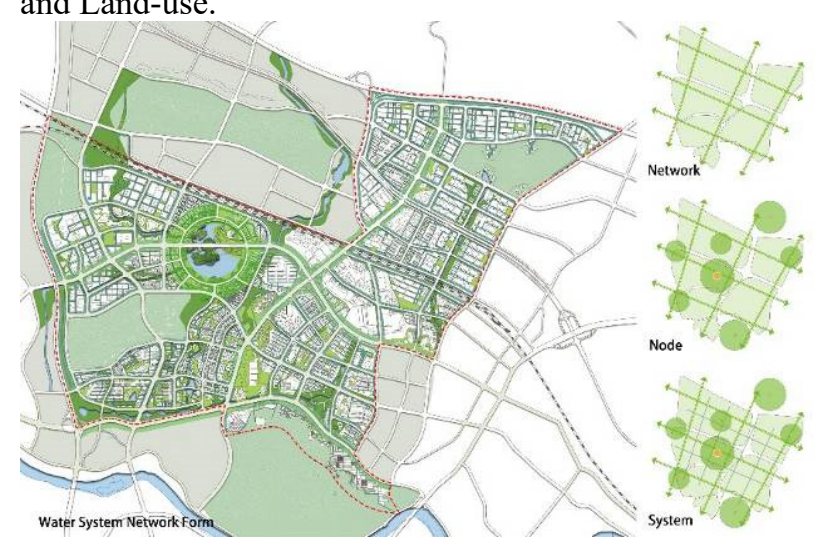

Fig. 11. The Water System Network of the Urban Design

\subsection{The Guidance and Control in Whole-scale}

According to the evaluation standard of sponge city construction, the project carries out low impact development and application of Sponge-city design technology in various processes and scales of urban design, combined with the local natural hydrological characteristics. On the urban scale, the urban rainfall convergence is decomposed and controlled combined with 
the idea of small watershed management in the Spongecity Model. The design area is divided into five sub-areas for independent accounting of Sponge-city indicators. The indicators such as the Capture Ratio of Total Annual Runoff Volume are controlled in sub-regions to define the objectives and requirements of the next stage of control (Table 1). In the area scale, the system carries out quantitative control of indexes for each control area and puts forward reasonable control index thresholds according to the specific conditions and problems of each control area (Table 2, taking Zone A as an example). Finally, it supplements the application requirements and suggestions of ecological infrastructure and sponge-city technology, in the urban design guidelines on the block scale.

Table 1. Zoning Control of Sponge-city Index

\begin{tabular}{|c|c|c|c|c|c|}
\hline Zone Location Map & No. & Zone Name & Area $(\mathrm{km} 2)$ & $\begin{array}{c}\text { Capture Ratio of Total Annual } \\
\text { Run-off Volume (\%) }\end{array}$ & $\begin{array}{c}\text { Catchment } \\
\text { Outlet }\end{array}$ \\
\hline & 1 & Zone A & 4.83 & 83 & Taozi Lake \\
\hline & 2 & Zone B & 2.86 & 82 & Chenjiaba Canal \\
\hline & 3 & Zone $\mathrm{C}$ & 4.37 & 81 & Liujiawan \\
\hline & 4 & Zone D & 1.46 & 80 & Liujiawan \\
\hline & 5 & Zone E & 2.84 & 81 & Liujiawan \\
\hline & & Total & 16.36 & 82 & Lujiang River \\
\hline
\end{tabular}

Table 2. Sponge-city District Control Index System (Zone A)

\begin{tabular}{|c|c|c|c|c|}
\hline \multirow{2}{*}{$\begin{array}{c}\text { Index } \\
\text { attributes }\end{array}$} & \multicolumn{2}{|c|}{ Mandatory Index Section } & \multicolumn{2}{|l|}{ Guiding Index Section } \\
\hline & Index & Value & Index & Value \\
\hline \multirow{3}{*}{$\begin{array}{l}\text { Water } \\
\text { Ecology }\end{array}$} & $\begin{array}{l}\text { Capture Ratio of Total } \\
\text { Annual Run-off Volume }\end{array}$ & $83 \%$ & $\begin{array}{l}\text { Superficial Sinking Style LID Area } \\
\left(\mathrm{hm}^{2}\right)\end{array}$ & 37.15 \\
\hline & $\begin{array}{l}\text { Ecology Shoreline } \\
\text { Reconstruction Rate }\end{array}$ & $90 \%$ & Green Roof Area $\left(\mathrm{hm}^{2}\right)$ & 19.94 \\
\hline & & & Permeable Pavement Area $\left(\mathrm{hm}^{2}\right)$ & 29.98 \\
\hline \multirow{4}{*}{$\begin{array}{l}\text { Water } \\
\text { Security }\end{array}$} & Flood Control Standard & 50 years frequency & $\begin{array}{l}\text { Planning Rainwater Pipeline Length } \\
\text { (m) }\end{array}$ & 13124 \\
\hline & Catchment Outlet & Taozi Lake & River Regulation Length (m) & 3000 \\
\hline & Pipeline Return Period & 2 years frequency & & \\
\hline & Waterlogging Standard & 20 years frequency & & \\
\hline \multirow{5}{*}{$\begin{array}{c}\text { Water } \\
\text { Environment }\end{array}$} & Water Quality Target & IV & COD Removal Amount (t) & 380 \\
\hline & COD Removal Ratio & $74 \%$ & NH3-N Removal Amount (t) & 287 \\
\hline & SS Removal Ratio & $89 \%$ & SS Removal Amount (t) & 216.7 \\
\hline & TP Removal Ratio & $77 \%$ & TP Removal Amount (t) & 4.82 \\
\hline & NH3-N Removal Ratio & $80 \%$ & & \\
\hline $\begin{array}{c}\text { Water } \\
\text { Resources }\end{array}$ & $\begin{array}{l}\text { Rainwater Resources } \\
\text { Utilization Ratio }\end{array}$ & $10 \%$ & $\begin{array}{l}\text { Rainwater Utilization Amount } \\
\left(\mathrm{m}^{3} / \text { year }\right)\end{array}$ & 129,000 \\
\hline
\end{tabular}

\subsection{Urban Design of Water and Land-use Conjugation}

In the process of deepening waterfront space form, the design emphasizes the following aspects (taking Taozi Lake area as an example): Firstly, the design improves the utilization efficiency of hydrophilic coastline, through the optimization of coastline morphology and the integration of spatial functions. It plans commercial, cultural, recreational and residential functions in the outer ring area, controls the size of buildings in a road network form of walking suitable, for improving the attraction and accessibility of space. Secondly, the design enhances the comfort experience of space users in somatosensory and psychological aspects and optimizes the architectural form and space landscape. Through the urban design guidelines, it puts forward the control requirements of waterfront space types and shoreline types, to form a unified waterfront space style and characteristics, for strengthening the symbolic local characteristics. Thirdly, considering different seasons and rainfall conditions, it focuses on the storage function of the water landscape, for improving the ecological effect and utilization efficiency.

\section{Conclusions}

From the conception stage of the project, the design process of $\mathrm{CCV}$ regards the protection and utilization of water resources as the focus of space research and realizes the ecological development of the new district through scientific management and reasonable application of water resources. The project practice process attempts to integrate waterfront ecological space planning techniques and design methods in each design stage to realize effective protection and control of water resource element systems. The whole process of urban design ensures the systematic guidance and control of water resources from macro to micro. It explores the balance point and optimal 
solution between water ecological environment protection and the improvement of human settlements waterfront space quality. The attempt provides practical experience for the conjugate development of water and land-use in urban space. The project practice only reflects the preliminary progress of the research. In the subsequent theoretical research and project practice, the water cycle status of the design area will be watched and the relevant data will be collected continuously. According to the feedback information, the project will evaluate the rationality and effectiveness of design techniques and methods comprehensively, and propose the path and content of theoretical deepening and design optimization for future design.

\section{Acknowledgments}

This paper is one of the phased achievements of the science and technology foundation project in Liaoning, China "Research on Key Technologies of urban waterfront spatial form guidance and control based on conjugation of water health and economic vitality" (2019-ZD-0680).

\section{References}

1. Ahiablame, L. M., Engel, B. A., Chaubey, I. (2012) Effectiveness of low impact development practices: literature review and suggestions for future research, Water Air \& Soil Pollution, 223: 4253-4273.

2. McHarg, I. L. (2005) Design with Nature, Tianjin University Press, Tianjin.

3. Cheng S.D. (2015) Urban design in lakefront areas based on water environment protection, Architectural Journal, S1: 35-39.

4. Wang X.F., Liu H., Yuan X.Z., Ren H.Q., Yue J.S. and Xiong S. (2016) Construction of the urban water environmental pollution control system based on the ecological ideas of water sensitive urban design, Acta Ecologica Sinica, 36(1): 30-43.

5. Chen T., Li Y.L. (2018) Urban design strategies of urban water environment orientation based on the perspective of eco-vulnerability, Chinese Landscape Architecture, 12: 17-22.

6. Liu S.J., Li W.T. and Shi P. (2018) Layers strategy of sponge city design on water environment, Planners, 34(5): 128-131.

7. Guo Z.G., Liu W. and Zhou X. (2016) Water-oriented urban spatial planning and implementation method: the practice of statutory planning in Tianjin Binhai new area, Chinese Landscape Architecture, 32(4): 6873.

8. Li Y.F., Liu H.Y., Zhang H.B., SUN Y.M. and Li Y.L. (2015) The study of landscape health based on landscape structure and water environment: a case study of Xixi wetland park in Hangzhou, Journal of Natural Resources, 30(5): 761-770. 